\title{
A study of predictors of adolescents' physical activity intentions
}

\author{
Lambros Lazuras ${ }^{1}$, Despoina Ourda ${ }^{2}$, Vassilis Barkoukis ${ }^{2 *}$ and Haralambos Tsorbatzoudis ${ }^{2}$ \\ ${ }^{1}$ South East European Research Centre (SEERC), Greece \\ ${ }^{2}$ Aristotle University of Thessaloniki, Greece
}

(Received September 3, 2011; Accepted October 15, 2011)

\begin{abstract}
The present study used an integrated theoretical framework based on the Theory of Planned Behaviour and the Prototype/Willingness model to examine the social cognitive predictors of leisure time physical activity intentions among Greek secondary school students $(\mathrm{N}=254, \mathrm{M}$ age $=13.59$ years, $\mathrm{SD}$ $=1.18$ ). A cross-sectional survey method was employed to assess physical activity intentions and related psychosocial beliefs, as well as self-reported physical activity behaviour. Multiple regression analysis indicated that leisure time physical activity intentions were predicted by past behaviour, perceived behavioural control, and anticipated regret. Prototype similarity and favourability, and descriptive norms did not predict intentions. The findings are discussed in terms of the utility of the planned behaviour and prototype/willingness approaches to explain leisure time physical activity among young people.
\end{abstract}

Keywords: adolescence, anticipated regret, prototypes, social cognition.

\section{Un estudio de los predictores de la intención de práctica física en ado- lescentes}

RESUMEN: El presente estudio se realizó bajo un marco teórico basado en la Teoría de la conducta planificada y el modelo de prototipo y disposición para examinar los predictores socio-cognitivos de las intenciones de actividad física durante el tiempo libre entre estudiantes griegos de enseñanza secundaria $(\mathrm{N}=254$, Media $=13.59, \mathrm{DT}=1.18)$. Se llevó a cabo un estudio transversal para evaluar intenciones de actividad física y creencias psicosociales relacionadas, así como conductas de actividad física autoinformada. Un análisis de regresión múltiple indica que los predictores de las intenciones de actividad física durante el tiempo libre eran conducta pasada, control percibido de la conducta y arrepentimiento anticipado. Similitud de prototipo, favorabilidad y normas descriptivas no predecían las intenciones. Los hallazgos son planteados en términos de utilidad de la conducta planeada y enfoques para explicar la actividad física durante el tiempo libre entre la gente joven.

Palabras clave: adolescencia, arrepentimiento anticipado, prototipo, cognición social. 


\section{INTRODUCTION}

The long-term health benefits of physical activity are well documented (e.g., Fox, Boutcher, Faulkner, \& Biddle, 2000; Landers \& Arent, 2001). However, recent studies indicate that many children adopt sedentary lifestyles, and avoid engaging in regular physical activity (Boreham \& Riddoch, 2001; Strauss, Rodzilsky, Burack, \& Colin, 2001). Accordingly, large-scale epidemiological studies in the US and Northern Europe indicate that the greatest reduction in physical activity levels occurs in adolescence, a critical time period during which several health-compromising behaviours, including cigarette smoking, are initiated (Filice, Joseph, Hannan, \& Lando, 2003; Reyna \& Farley, 2006). Recent metaanalysis indicated that attitudes and beliefs about physical activity are among the critical variables that can enhance leisure time physical activity participation (Hagger \& Chatzisarantis, 2009). The consideration of relevant social cognitive theories can be particularly helpful in this task.

\section{Physical activity as a planned behaviour}

The Theory of Planned Behaviour (TPB; Ajzen, 1991) has been developed to explain voluntary behaviours, and has been used extensively in the health behaviour domain (Armitage \& Conner, 2000). The main tenet of the theory is that actions are preceded by effortful thinking and premeditation. In this line, behavioural intentions are seen as the immediate predecessor of actions, and reflect the person's commitment and determination to enact the behaviour in question (Armitage \& Conner, 2001; Conner \& Armitage, 1998). Intentions are shaped by one's attitudes, normative beliefs, and perceived behavioural control. Attitudes represent the combination of outcome expectancies (i.e., a behaviour will lead to specific outcomes), and the evaluation of these outcomes by the person (Ajzen, 2002; Sparks, Shepherd, \& Frewer, 1995). Subjective norms reflect perceived social pressures to conform and have been examined in relation to motivation to comply. Perceived behavioural control (PBC) denotes one's perceived ability to perform the target behaviour, and may predict behaviour either directly, or indirectly, via the intentions route, provided that perceptions of control reflect actual control over the behaviour in question rather than illusory control beliefs (Ajzen, 2002; Armitage \& Conner, 2001; Conner \& Armitage, 1998; Sheeran, Trafimow, \& Armitage, 2003).

Several studies have used the TPB to predict physical activity in adolescents. For instance, Mummery, Spence, \& Hudec (2000) showed that the TPB components significantly predicted adolescents' intentions to engage in physical activity, and that the effect of subjective norms was stronger among younger adolescents. Everson, Daley, \& Ussher (2007) found that attitudes, subjective norms, and $\mathrm{PBC}$ predicted intentions, and that intentions and $\mathrm{PBC}$ directly predicted physical activity among smoker adolescents. Also, several cross-cultural studies have shown that the TPB components significantly predicted physical activity 
intentions and behaviour in adolescents (Hagger et al., 2007; Saunders, Motl, Dowda, Dishman, \& Pate, 2004; Trost et al., 2002).

Within the context of physical activity, researchers have also considered the influence of additional variables not described in the original TPB model. One such variable is anticipated regret: the expectation to feel regret and related negative emotions from performing (or not performing) specific behaviours (Conner \& Armitage, 1998). Sheeran \& Orbell (1999) demonstrated that anticipated regret moderated the effects of intentions on behaviour, so that people were more likely to enact their intentions when they expected more regret from not performing the behaviour in question. Furthermore, Abraham \& Sheeran (2003) showed that anticipated regret moderated the effects of exercise intentions on behaviour, and that intentions predicted actual behaviour more strongly when anticipated regret was considered prior to intention formation. Nevertheless, although the aforementioned findings highlight the role of anticipated regret in predicting exercise intentions and behaviour among adults, previous studies have not examined the effects of anticipated regret on adolescent physical activity.

\section{Normative influences and prototype perceptions}

The TPB has included normative beliefs in order to strengthen the relationship between attitudes and behaviour. The narrow focus on subjective norms does not grasp the complexity and versatility of normative processes underlying behaviour, and does not account for other sources of normative influence, such as descriptive norms (i.e., perceptions of what other people typically do; Cialdini, 2003; Cialdini, Reno, \& Kallgren, 1990). A meta-analysis of TPB studies showed that descriptive norms significantly correlated with (average correlation $=.44$ ) and predicted intentions, over and above the effects of the TPB components (Rivis \& Sheeran, 2003a), whereas another study found that descriptive norms significantly predicted adolescents' intentions and actual behaviour after controlling for the effects of TPB variables (Rivis \& Sheeran, 2003b).

Another way of examining normative influences on behaviour regards the role of prototypes, which are defined as stored representations of the typical person that engages in the target behaviour (Gibbons \& Gerrard, 1995; Gibbons et al., 1998). Prototypes represent a core construct of the Prototype/Willingness Model (PWM), and assume a key role in motivating behaviour. Specifically, the closer individuals believe themselves to be to the prototype of, say, a smoker (prototype similarity), and the more favourable image they hold of this prototype (prototype favourability), the more likely they are to engage in the respective behaviour (i.e., smoking, Gibbons et al., 1998; 2004). Although these prototype perceptions (i.e., favourability and similarity) have been studied mainly in the context of adolescent risk-taking, a couple of studies have shown that they can also predict health promoting behaviour, such as physical activity, in young people both directly (Rivis \& Sheeran, 2003b) and through behavioural intentions (Rivis, Sheeran, \& Armitage, 2006). 


\section{The present study}

The present study aimed to integrate the aforementioned findings to predict adolescents' intentions to engage in leisure time physical activity. For this purpose an integrated social cognition model was used, which incorporated standard TPB variables, anticipated regret, descriptive norms, and prototype similarity and favourability. Finally, because past behaviour can have a profound effect on intention formation and on future behaviour through habituation (Armitage \& Conner, 2001; Conner \& Armitage, 1998), we examined the aforementioned social cognitive predictors of intentions after controlling for the effect of past engagement in physical activity. To the best of the authors' knowledge, this is the first time such a model is used in the study of adolescent physical activity. Based on previous literature, it was hypothesized that anticipated regret, descriptive norms and prototype perceptions would predict intentions, over and above the effects of other TPB variables (i.e., attitudes, subjective norms, and perceived behavioural control) and past behaviour.

\section{METHOD}

\section{Participants}

Three secondary public schools in the urban area of Thessaloniki (second largest Greek city, approx. 1 million inhabitants) were randomly selected, and all students attending the 8th and 9th grades were approached and agreed to participate. Students $(\mathrm{N}=254,46.5 \%$ females, $\mathrm{M}$ age $=13.59$ years, $\mathrm{SD}=1.18)$ were enrolled in typical coeducational classes and belonged to families of middle socioeconomic level.

\section{Measures}

Past behaviour. Self-reported physical activity was assessed with an adapted version of Godin \& Shephard's (1985) Leisure-Time Exercise Questionnaire (LTEQ). Independent evaluations of the LTEQ have found it to be valid, reliable, and easy to administer. Specifically, the LTEQ displays satisfactory concurrent validity with gold-standard measures of physical activity such as heart-rate monitoring (Jacobs, Ainsworth, Hartman, \& Leon, 1993), and the version used in the present study has been applied in previous research on the socialcognitive determinants of physical activity (Hagger, Chatzisarantis, \& Harris, 2006).

Participants were initially presented with the definition of vigorous physical activity given by Godin \& Shephard (1985). Vigorous physical activity was defined as all active sports and physical activities, but not low-level activities or walking to school. Following that, participants were asked to report how many times per week, on average, they engaged in vigorous physical activity over the 
previous five weeks. Responses were coded on an eight-point scale $(0=$ none, $7=$ seven times a week).

Theory of Planned Behaviour. The TPB measures used in the present study were developed according to the guidelines by Ajzen (1991). Attitudes to physical activity were assessed with two measures. The first measure included eight items reflecting different behavioural beliefs or perceived benefits of engaging in physical activity (e.g., 'my participation in physical activity will help me... control my body weight; make friends; feel better with myself; improve my health; increase self-confidence; relax; become distinct from others; improve my skills'). Responses were recorded on seven-point scale (from unlikely $=1$, to likely $=7$ ), and a mean score was calculated with higher scores indicating higher likelihood for positive exercise-related outcomes. The second measure adhered to Ajzen's (1991; 2003) suggestions and included a stem proposition 'I believe that engaging in physical activity is' followed by six seven-point semantic differentials (useless/useful; difficult/easy; unimportant/important; dull/interesting; unpleasant/pleasant; bad/good). A mean score was computed and higher scores reflected more positive attitudes to physical activity.

Subjective norm was measured with the proposition 'my engagement in physical activity will be approved by significant others such as' followed by three items (parents; friends; siblings) scored on a seven-point scale $(1=$ not at all, 7 $=$ very much). Higher scores reflected greater perceived acceptance of physical activity by significant others. In subsequent analyses, subjective norms were assessed as the mean of the three-item composite measure.

Perceived behavioural control (PBC) was assessed with the mean of three items (e.g., 'if I wanted, I could participate in physical activity next month') scored on a seven-point scale, with higher scores denoting greater perceived control over physical activity.

Intentions to engage in physical activity were measured with the mean of three items ('I intend to engage in physical activity in the next month,' 'I will try to engage in physical activity in the next month,' 'I am determined to engage in physical activity in the next month'), scored on a seven-point scale (e.g., $1=$ strongly disagree, 7 = strongly agree), with higher scores reflecting stronger behavioural intentions. Digelidis \& Papaioannou (1999) supported the validity and reliability of the measures of planned behaviour theory with Greek adolescents.

Prototype perceptions. Actor prototypes in this study were defined as same age peers who engage in physical activities on a regular basis. Favourability of actor prototypes was measured with an adapted version of the measure used by Rivis et al. (2006). Specifically, a modified version of the evaluation thermometer (Haddock \& Zanna, 1981) was used, and asked 'how would you define people your age who engage regularly in physical activities?'. Responses were coded on a 10 -point scale $(1=10,10=100)$, and seven semantic differentials were used (fool/smart; immature/mature; boring/interesting; with low self-esteem/ with high self-esteem/not at all independent/independent; not at all popular/very popular; unlikable/likable). A mean score was calculated, with higher scores re- 
flecting greater favourability towards same age peers who engage in physical activity on a regular basis.

Also, prototype similarity was assessed with an adapted version of the measure used by Rivis et al. (2006). Specifically the question 'how similar do you think you are to people your age who engage in physical activity on a regular basis?' was used and responses were recorded on a seven-point scale ( $1=\mathrm{I}$ am not similar at all, $7=\mathrm{I}$ am very similar), with higher scores indicating greater perceived similarity to the actor prototype. Ourda (2009) provided evidence on the reliability and construct validity of the measures of the Prototype/Willingness Model in Greek adolescents.

Descriptive norms. Descriptive norms were measured with two questions. The first was open-ended and required participants to estimate how many (out of $100 \%$ ) of their same age peers in Greece engaged regularly in physical activities. The second question asked how many of participants' five closest friends engaged regularly in physical activities, and responses were coded on a six point continuous scale (from none of them to all of them). Ourda (2009) provided evidence on the reliability and construct validity of the descriptive norms' measure in Greek adolescents.

Anticipated regret._Anticipated regret was assessed with the stem proposition 'if I do not engage in physical activities in the next month I will' followed by three different statements reflecting anticipated negative emotions (regret it, feel bad about myself, be disappointed). Responses were coded on a seven point scale ( $1=$ definitely not, 7 = definitely yes), and a mean score was calculated. Higher scores denoted more anticipated regret from not engaging in physical activity in the next month. Barkoukis, Lazuras, Ourda, Galanis \& Oxyzoglou (2009) provided evidence on the reliability and construct validity of this scale with Greek adolescents.

\section{Procedure}

The principals and PE teachers of the participating schools were informed about the aims and purposes of the study and permission was granted. Also, following international ethical guidelines for behavioural research, informed consent was sought from participants and their parents and/or caregivers. The students completed anonymous questionnaires in a quiet environment during regular PE classes at school, without the presence of their physical education teacher, and under the supervision of experienced research assistants. Both oral and written instructions were given regarding the content and the completion of the questionnaires, and the students were reassured about the confidentiality of their responses, as well as their right to withdraw at any time during the completion of the questionnaires. Survey completion lasted approximately 20 minutes. 


\section{RESULTS}

\section{Descriptive statistics}

All the multi-item continuous measures used in the study had satisfying internal consistency reliability scores (Cronbach's $\alpha>.71$ ). Means, standard deviations, and internal consistency reliability scores of the measures used are presented in Table 1.

Table 1. Means, SDs, and Internal Consistency Scores for the Measures Used in the Study

\begin{tabular}{|lcccc|}
\hline & Nof items & $M$ & $S D$ & Cronbach's $\alpha$ \\
\hline Past behaviour (LTEQ) & 1 & 54.6 & 27.0 & - \\
TPB variables & & & & \\
$\quad$ Intentions & 3 & 5.34 & 1.68 & 0.88 \\
$\quad$ Attitudes (semantic differential) & 6 & 6.04 & 0.81 & 0.76 \\
Attitudes (perceived benefits) & 8 & 5.46 & 0.94 & 0.73 \\
Subjective norms & 3 & 5.03 & 1.65 & 0.72 \\
PBC & 3 & 5.34 & 1.32 & 0.71 \\
P/W variables & & & & \\
$\quad$ Prototype favourability & 7 & 44.9 & 35.5 & 0.98 \\
$\quad$ Prototype similarity & 1 & 4.76 & 1.42 & - \\
Descriptive norms & & & & \\
$\quad$ Perceived prevalence (\% peer group) & 1 & 65.5 & 19.4 & - \\
$\quad$ Best friends's behaviour & 1 & 4.11 & 1.30 & - \\
Anticipated regret & 3 & 4.52 & 1.80 & 0.87 \\
\hline
\end{tabular}

\section{Bivariate correlations}

Correlation (Pearson's $r$ ) analysis was used in order to assess the construct validity of the measures used in the study. Significant correlations $(\mathrm{p}<.05)$ were observed in accordance to theoretical expectations, thus reflecting adequate construct validity of the measures. Specifically, all TPB variables and anticipated regret were correlated with each other and with intentions to engage in physical activity. Prototype measures were also related to some TPB variables, descriptive norms, and anticipated regret. Intercorrelations among the study variables are presented in Table 2. 
Table 2. Intercorrelations Between the Study Variables $(N=254)$

\begin{tabular}{|c|c|c|c|c|c|c|c|c|c|}
\hline & 1 & 2 & 3 & 4 & 5 & 6 & 7 & 8 & 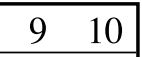 \\
\hline 1. Intentions & - & $.32 *$ & $.37 *$ & $.16^{*}$ & $.59 *$ & .04 & $.29 *$ & .08 & $.28 * .54 *$ \\
\hline $\begin{array}{l}\text { 2. Attitudes (semantic } \\
\text { differential) }\end{array}$ & & 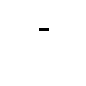 & $.49 *$ & .09 & $.39 *$ & $.13^{*}$ & $.23 *$ & .00 & $.17 * .40 *$ \\
\hline $\begin{array}{l}\text { 3. Attitudes (perceived } \\
\text { benefits) }\end{array}$ & & & - & $.19 *$ & $.35^{*}$ & .09 & $.17 *$ & .01 & $.22 * 41 *$ \\
\hline 4. Subjective norms & & & & - & $.23 *$ & .00 & $.15^{*}$ & .03 & $.08 .17 *$ \\
\hline 5. $\mathrm{PBC}$ & & & & & - & .01 & $.43 *$ & .07 & $.28 * .41 *$ \\
\hline 6. Prototype favourability & & & & & & 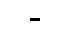 & -0.1 & $.17 *$ & -.09 .11 \\
\hline 7. Prototype similarity & & & & & & & - & .08 & $.17 * .24 *$ \\
\hline $\begin{array}{l}\text { 8. Perceived prevalence }(\% \\
\text { peer group) }\end{array}$ & & & & & & & & - & $.27 *-.02$ \\
\hline 9. Best friends' behaviour & & & & & & & & & $-.25 *$ \\
\hline 10. Anticipated regret & & & & & & & & & - \\
\hline
\end{tabular}

Note. $* p<.05$.

\section{Predicting intentions to engage in physical activity}

A hierarchical regression analysis was completed at three steps. Because of its well-documented effect on intentions and future behaviour, past behaviour (i.e., self-reported physical activity) was entered at the first step, and the remaining predictors were entered at subsequent steps. The rationale for this ordering was to examine the unique contribution of each predictor variable after controlling for the effects of past behaviour. Overall, a significant model emerged, $F$ $(10,172)=16.77, p<.0005$, predicting $47.8 \%\left(\operatorname{Adj} R^{2}\right)$ of the variance in physical activity intentions. Tolerance levels were high $(>.569)$ at all three steps of the analysis, reflecting no multicollinearity among the predictor variables.

More specifically, past behaviour exerted a significant effect on intentions, and predicted $5.9 \%$ of the variance. The variables from the TPB (i.e., attitudes, subjective norms, and $\mathrm{PBC}$ ) were entered at the second step and increased predicted variance in intentions by $36.3 \%$. Nevertheless, only PBC had a significant effect. At the final step descriptive norms, prototype perceptions, and anticipated regret were entered. Predicted variance was significantly increased by $8.2 \%$ at the last step, but only anticipated regret was significant predictor. The predictors of intentions to engage in physical activity at each step are shown in Table 3. 
Table 3. Predictors of Intentions to Engage in Physical Activity $(N=242)$

\begin{tabular}{|clcc|}
\hline Step & \multicolumn{1}{c}{ Predictors } & $\beta$ & $\operatorname{Adj} R^{2}$ \\
\hline 1 & Past behaviour & $.254^{*}$ & .059 \\
\hline 2 & Past behaviour & $.245^{*}$ & .410 \\
& Attitudes (semantic differential) & .091 & \\
& Attitudes (perceived benefits) & .140 & \\
& Subjective norms & -.038 & \\
& PBC & $.488^{*}$ & \\
\hline & Past behaviour & $.253^{*}$ & .478 \\
& Attitudes (semantic differential) & -.010 & \\
Attitudes (perceived benefits) & .101 & \\
& Subjective norms & -.028 & \\
PBC & $.365^{*}$ & \\
Prototype favourability & -.001 & \\
& Prototype similarity & .038 & \\
& Descriptive norms (best friends & .023 & \\
who exercise) & .081 & \\
Descriptive norms (perceived & & \\
prevalence) & $.340^{*}$ & \\
Anticipated regret & & \\
\hline
\end{tabular}

Note: ${ }^{*} p<.001$.

\section{DISCUSSION}

The present study set out to examine the psychosocial predictors of adolescent physical activity by using concepts from research in two different theoretical models, namely, the TPB and PWM. It was expected that TPB variables, descriptive norms, prototype perceptions, and anticipated regret would predict physical activity intentions. Nevertheless, the findings showed that, among the TPB variables, only perceived behavioural control retained a significant effect, over and above the effect of past behaviour. Furthermore, anticipated regret, which was added at the last step of the analysis, had a significant effect on intentions, after controlling for past behaviour and perceived behavioural control. This agrees with the findings by Abraham \& Sheeran (2003), where anticipated regret predicted adults' exercise intentions, over and above TPB variables, and indicates that anticipated regret is an important variable that should be included in future research of adolescent physical activity.

Nonetheless, contrary to our hypotheses and previous findings (e.g., Hagger et al., 2007; Mummery, Spence, \& Hudec, 2000), the present findings showed that standard TPB variables, such as attitudes and subjective norms, did not predict physical activity intentions. This was also the case for the variables derived from the P/W model, namely actor prototype favourability and similarity. Firstly, 
these findings indicate that perceived behavioural control and anticipated regret were the most important predictors of adolescents' leisure time physical activity intentions. Traditionally, TPB has been formulated to account for the relationship between attitudes and behaviour (Armitage \& Conner, 2001; Conner \& Armitage, 1998). Yet, our findings suggest that attitudes could not explain leisure time physical activity of the young people participating in this study. Instead, a different approach grasping issues more pertinent to behavioural control and anticipated regret may be more helpful. Practically, this means that interventions to increase young people's motivation to engage in leisure time physical activity may benefit more by targeting 'can do' and 'how to do' beliefs, instead of simply conveying messages about the benefits of exercise.

Secondly, contrasting the findings by Rivis et al. (2006), the present study indicates that actor prototypes do not seem to play a role in intention formation for an otherwise health promoting behaviour (i.e., leisure time physical activity). Still, these findings refer only to the specific population studied and may reflect cultural influences not captured by studies in other countries. Specifically, given that Greece is ranked among the top European countries with the highest adolescent obesity and physical inactivity rates, it might be the case that pro-health prototypes are not vivid enough, or accessible from memory. As a result, Greek adolescents may not have a clear picture of the people who regularly engage in exercise, and, therefore, prototype perceptions can hardly influence their intentions and behaviour.

Overall, the present findings indicate that leisure time physical activity in Greek adolescents can hardly be seen as a process triggered by stored prototypes or other sorts of normative influences, such as following the behaviour of others, or conforming to socially acceptable behavioural standards. A possible explanation is that factors related to behavioural control, such as having access to specific equipment for physical activity (e.g., balls or athletic gear/apparel/ attire), and time constraints typical to the schedule of an adolescent student, are more important than normative and attitudinal beliefs. In short, adolescents may believe that exercising outside school is a good thing to do, and would probably engage in exercise if their peers were also exercising; still, finding the time and the means to do so may be more important.

Although the findings appear important and theoretically relevant, there are some limitations that need to be mentioned. Specifically, the validity of the finding would be improved should a more representative sample of adolescents was used. This would also allow for generalization of the findings to the wider population. Secondly, the dependent variable in the present study was behavioural intentions and not behaviour itself. This implies that the predictors of intentions are not necessarily predictors of the actual behaviour and vice versa (Webb \& Sheeran, 2006). That is, normative beliefs and prototypes were non-significant predictors of intentions, yet this does not mean that these variables do not have an effect on behaviour. Accordingly, anticipated regret may be important in intention formation, but the present findings cannot support a direct effect on ado- 
lescent physical activity. Notwithstanding these limitations, the present study had several strengths. Firstly, this was the first time the specific theoretical integration was applied in the context of adolescent physical activity. Integration of theoretical models is a current trend in psychological research and can be particularly helpful in better understanding several health behaviours (Hagger, 2009). Our study's contribution in better understanding adolescent physical activity was the assessment of anticipated regret after controlling for a range of other factors with well-documented effects on intentions and behaviour. This was an innovative feature that further extends previous research with adults on the effects of regret on physical activity (e.g., Abraham \& Sheeran, 2003). Secondly, reliable measures derived from previous research (e.g., Rivis et al., 2006) were used in this study, and thus allowed direct comparisons with past findings. Thirdly, the present findings were important because they suggest that cultural influences may play a role in understanding the effects of some variables (e.g., prototypes) on behaviour. Future studies are needed to validate the present findings, and further address additional predictors of adolescent physical activity.

\section{REFERENCES}

Abraham, C., \& Sheeran, P. (2003). Acting on intentions: The role of anticipated regret. British Journal of Social Psychology, 42, 495-511.

Ajzen, I. (1991). The theory of planned behaviour. Organizational Behaviour \& Human Decision Processes, 50, 179-211.

Ajzen, I. (2002). Perceived behavioural control, self-efficacy, locus of control, and the theory of planned behaviour. Journal of Applied Social Psychology, $32,665-683$.

Armitage, C. J., \& Conner, M. (2000). Social cognition models and health behaviour: A structured review. Psychology \& Health, 15, 173-189.

Armitage, C. J., \& Conner, M. (2001). Efficacy of the theory of planned behaviour: A meta-analytic review. British Journal of Social Psychology, 40, 471-499.

Barkoukis, V., Lazuras, L, Ourda, D., Galanis, D., \& Oxyzoglou N. (2009). The effect of anticipated regret on leisure-time physical activity during adolescence. Hellenic Journal of Physical Education and Sport, 29, 262-277.

Boreham, C., \& Riddoch, C. (2001). The physical activity, fitness and health of children. Journal of Sports Sciences, 19, 915-929.

Cialdini, R. B. (2003). Crafting normative messages to protect the environment. Current Directions in Psychological Science, 12, 105-109.

Cialdini, R. B., Reno, R. R., \& Kallgren, C. A. (1990). A focus theory of normative conduct: Recycling the concept of norms to reduce littering in public places. Journal of Personality and Social Psychology, 58, 1015-1026.

Cohen, J. (1988). Statistical power analysis for the behavioural sciences. Hillsdale: Lawrence Erlbaum.

Conner, M., \& Armitage, C. A. (1998). Extending the theory of planned beha- 
viour: A review and avenues for further research. Journal of Applied Social Psychology, 28, 1429-1464.

Digelidis, N., \& Papaioannou, A. (1999). Age-group differences in intrinsic motivation, goal orientations and perceptions of athletic competence, physical appearance and motivational climate in Greek physical education. Scandinavian Journal of Medicine \& Science in Sports, 9, 375-380.

Everson, E. S., Daley, A. J., \& Ussher, M. (2007). The theory of planned behaviour applied to physical activity in young people who smoke. Journal of Adolescence, 30, 347-351.

Fox, K. R., Boutcher, S. H., Faulkner, G. E., \& Biddle, S. J. H. (2000). The case for exercise in the promotion of mental health and psychological well-being. In S. J. H. Biddle, K. R. Fox, \& S. H. Boutcher (Eds.), Physical activity and psychological well-being (pp. 1-9). London: Routledge.

Filice, G. A., Joseph, A. M., Hannan, P. J., \& Lando, H. A. (2003). A period of increased susceptibility to cigarette smoking among high school students. Journal of School Health, 73, 272-279.

Gibbons, F. X., \& Gerrard, M. (1995). Predicting young adults health risk behaviour. Journal of Personality and Social Psychology, 69, 505-517.

Gibbons, F. X., Gerrard, M., Blanton, H., \& Russell, D. W. (1998). Reasoned action and social reaction: Willingness and intention as independent predictors of health risk. Journal of Personality and Social Psychology, 74, 1164-1180.

Gibbons, F. X., Gerrard, M., Vande Lune, L. S., Wills, T. A., Brody, G., \& Conger, R. D. (2004). Context and cognitions: Environmental risk, social influence, and adolescent substance use. Personality and Social Psychology Bulletin, 30, 1048-1061.

Godin, G., \& Shephard, R. J. (1985). A simple method to assess exercise behaviour in the community. Canadian Journal of Applied Sport Sciences, 10, 141-146.

Haddock, G., \& Zanna, M. P. (1994). Preferring housewives to feminists: Categorization and the favourability of attitudes towards women. Psychology of Women Quarterly, 18, 25-52.

Hagger, M. (2009). Theoretical integration in health psychology: Unifying ideas and complementary explanations. British Journal of Health Psychology, 14, 189-194.

Hagger, M. S., Chatzisarantis, N. L. D., Barkoukis, V., Wang, J. C. K., Hein, V., Pihu, M., Soos, I., \& Karsai, I. (2007). Cross-cultural generalizability of the theory of planned behavior among young people in a physical activity context. Journal of Sport \& Exercise Psychology, 29, 1-20.

Hagger, M. S., Chatzisarantis, N. L., \& Harris, J. (2006). From psychological need satisfaction to intentional behavior: Testing a motivational sequence in two behavioral contexts. Personality and Social Psychology Bulletin, 32, 131-148.

Jacobs, D. R. Jr., Ainsworth, B. E., Hartman, T. J., \& Leon, A. S. (1993). A simultaneous evaluation of 10 commonly used physical activity questionnaires. 
Medicine \& Science in Sports and Exercise, 25, 92-98.

Landers, D. M., \& Arent, S. M. (2001). Physical activity and mental health. In H. A. Hausenblas, \& C. M. Janelle (Eds.), Handbook of Research in Sport Psychology (2nd ed.) (pp. 740-765). New York: John Wiley and Sons.

Mummery, W. K., Spence, J. C., \& Hudec, J. C. (2000). Understanding physical activity intention in Canadian school children and youth: An application of the theory of planned behaviour. Research Quarterly in Exercise \& Sports, 71, 116-124.

Ourda, D. (2009). Application of the Prototype/Willingness Model to enhance health behaviours through physical education lessons. Unpublished Master Thesis. Aristotle University of Thessaloniki, Thessaloniki, Greece

Reyna, V. F., \& Farley, F. (2006). Risk and rationality in adolescent decision making. Psychological Science in the Public Interest, 7, 1-44.

Rivis, A., \& Sheeran, P. (2003a). Descriptive norms as an additional predictor in the theory of planned behaviour: A meta-analysis. Current Psychology, 22, 218-233.

Rivis, A., \& Sheeran, P. (2003b). Social influences and the theory of planned behaviour: Evidence for a direct relationship between prototypes and young people's exercise behaviour. Psychology and Health, 18, 567-583.

Rivis, A., Sheeran, P., \& Armitage, C. J. (2006). Augmenting the theory of planned behaviour with the prototype/willingness model: Predictive validity of actor versus abstainer prototypes for adolescents' health protective and health-risk intentions. British Journal of Health Psychology, 11, 483-500.

Saunders, R. P., Motl, R. W., Dowda, M., Dishman, R. K., \& Pate, R. R. (2004). Comparison of social variables for understanding physical activity in adolescent girls. American Journal of Health Behaviour, 28, 426-436.

Sheeran, P., \& Orbell, S. (1999). Augmenting the theory of planned behaviour: Roles of anticipated regret and descriptive norms. Journal of Applied Social Psychology, 29, 2107-2142.

Sheeran, P., Trafimow, D., \& Armitage, C. J. (2003). Predicting behaviour from perceived behavioural control: Tests of the accuracy assumption of the theory of planned behaviour. British Journal of Social Psychology, 42, 393-411.

Sparks, P., Shepherd, R., \& Frewer, L. J. (1995). Assessing and structuring attitudes towards the use of gene technology in food production: The role of perceived ethical obligation. Basic and Applied Social Psychology, 16, 267-285.

Strauss, R. S., Rodzilsky, D., Burack, G., \& Colin, M. (2001). Psychosocial correlates of physical activity in healthy children. Archives of Pediatrics \& Adolescent Medicine, 155, 897-902.

Trost, S. G., Pate, R. R., Dowda, M., Ward, D. S., Felton, G., \& Saunders, R. (2002). Psychosocial correlates of physical activity in white and AfricanAmerican girls. Journal of Adolescent Health, 31, 226-233.

Webb, T. L., \& Sheeran, P. (2006). Does changing behavioural intentions engender behaviour change? A meta-analysis of the experimental evidence. Psychological Bulletin, 132, 249-268. 